\title{
La indebida interpretación de la norma y el caso Space-Calamar ${ }^{1}$
}

\section{The wrong interpretation of the rule and the case Space-Calamar}

\author{
Camilo Enrique Cubillos Garzón ${ }^{2}$
}

\section{RESUMEN}

Este artículo explica por qué la Superintendencia de Industria y Comercio (Resolución 13895) desconoció el Ordenamiento Civil colombiano cuando se omitió el orden de prelación de créditos con el fin de proteger los derechos del consumidor; el origen legal de esta institución no permite su desconocimiento por parte de autoridades administrativas y judiciales. El consumidor, por sus características especiales, solo puede ser visto como un acreedor quirografario; la Resolución 13895 otorgó a los consumidores prioridad sobre aquellos acreedores con privilegio y preferencia. Un acto administrativo desconoció un expreso mandato de la ley.

Palabras clave: Consumidor, Prelación de Créditos, Space-Calamar, Acreedor Quirografario, Prevalencia de la Ley.

1 Fecha de recepción: 30 de agosto de 2018. Fecha de aceptación: 5 de diciembre de 2018. Para citar el artículo: Cubillos C. "La indebida interpretación de la norma y el caso Space-Calamar". En Revist@E-Mercatoria, vol. 17, n. ${ }^{\circ}$ 2. julio-diciembre 2018. Con la colaboración de Juan José Sotelo Enríquez. (2016) y Sofía Urrea Zuluaga (2018). DOI: https://doi. org/10.18601/16923960.v17n2.04

2 Abogado, Universidad Externado de Colombia; Especialista en Derecho de los Negocios, Universidad Externado de Colombia ${ }_{i}$ Máster en Derecho de Empresa, Universitat Pompeu Fabra, Barcelona, España; Diploma de Estudios Avanzados en el Doctorado del Derecho con Especialización en Derecho Patrimonial, Universitat Pompeu Fabra, Barcelona, España ${ }_{i}$ y Doctorado en Derecho, Universitat de Valencia, España. cecubillos@yahoo.es 


\begin{abstract}
This article explains why the Superintendence of Industry and Commerce (Administrative Resolution 13895) ignored the Colombian legal system when the order of priority of credits was omitted in order to protect consumer's rights; the legal origin of this institution does not allow its ignorance on the part of administrative and judicial authorities. The consumer, due to its special characteristics, can only be seen as an unsecured creditor; Administrative Resolution 13895 granted consumers priority over those creditors with privilege and preference. An administrative act ignored an express mandate of the law.
\end{abstract}

Keywords: Consumer, Priority of Credits, Space-Calamar, Unsecured Creditor, Prevalence of the Law.

\title{
INTRODUCCIÓN
}

Cuando se propuso tratar un asunto relacionado con El Consumidor, fue de gran satisfacción encontrar una infinidad de parámetros que cabrían ser expuestos en estas cortas líneas, sin embrago era evidente que, a pesar de existir razones de peso para proteger los objetivos de aquellos terceros o usuarios, no era suficiente aquel motivo para lograr desconocer los límites jurídicos existentes en el Derecho.

Con el fin de comprender, así como el de exponer un asunto como es el de los consumidores, se hace necesario aclarar el contexto desde donde se abordará, para ello deberá recurrirse a una descripción general de las fuentes jurídicas del Ordenamiento que le sirven de soporte, para luego adentrarse en la órbita del Consumidor al interior de la legislación colombiana.

De igual forma, ha de pasarse además de la concepción de consumidor por la descripción de los deberes y riesgos que aquella tarea del consumo involucra, todo ello al hacer parte de un movimiento oscilante como es el del Mercado.

Una vez aclarado este punto, surge la necesidad de explicar las irregularidades existentes; muchos son los hechos que motivan la aparición de una sistematización jurídica, no obstante, jamás podría bajo esta figura desconocerse los derechos ya adquiridos por otros sujetos, pese a tratarse de temas mercantiles nacionales donde ha de primar el interés general sobre el particular.

Lo que efectivamente es equívoco e incomprensible, es que bajo el manto protector de la Ley y en la búsqueda de la defensa de terceros (consumidor), se abuse de las propias normas o se termine desconociendo el trámite legal existente para reformar o interpretar la Ley a través de otras fuentes jurídicas del Derecho de rango inferior, como es el caso de emplear una Resolución de la Superintendencia de Industria y Comercio (SIC). 
Demos paso de esta manera, a un estudio de las irregularidades en torno a la interpretación normativa de un asunto generado alrededor de los consumidores.

\section{GENERALIDADES CONCEPTUALES}

\section{A. Fuentes Jurídicas del Ordenamiento Colombiano}

\section{La Ley}

Así como se expuso en el acápite introductorio, el contexto que rodeará el asunto del consumidor será el de las fuentes normativas que han de servido de soporte; para conseguirlo, debemos acudir a la concepción de la Ley adentrándonos en el ámbito comparativo con otros mecanismos regulatorios, logrando de esta manera acudir a unas reglas generales de interpretación normativa o lo que en otros términos significaría, observar y apreciar la pirámide de prelación de las fuentes jurídicas.

Así las cosas, la primera característica de la Ley es que se trata de una regla que ha sido establecida por una autoridad superior con el fin de organizar las conductas o aspectos trascendentales en la Sociedad para instaurar el orden político, social y justo, garantizando la igualdad, la convivencia y la justicia, dispuestas en la Constitución Nacional.

Un segundo aspecto distintivo de la Ley, son los procedimientos que existen para la validez y eficacia de la misma; sobre el particular y con el fin de concretar aquellas imposiciones del legislador, bien se pueden reducir a los debates originados dentro de un órgano superior (Actos del Congreso -Senado y Cámara-) $)^{3}$, su votación, la sanción presidencial y en algunos eventos, un control por parte de la Corte Constitucional.

En definitiva y dentro del marco explicativo, aquellas normas se encuentran circunscritas a la expedición por parte de un órgano superior y que fue escogido de manera democrática.

Si bien es cierto que la Ley se halla dotada de unas particularidades especiales que la hacen la segunda fuente jurídica más importante del Ordenamiento Jurídico, siendo la principal la Constitución Nacional ${ }^{4}$, no lo es menos, que las demás fuentes jurídicas (propias e impropias) se encuentran subordinadas a estas, tal y como son los Actos Administrativos -Resoluciones- ${ }^{5}$, la Jurisprudencia y los Principios Generales del Derecho, entre otras.

3 Vidal Perdomo, Jaime. Derecho Administrativo. Novena Edición. Ed. Temis. Bogotá. 1987. p. 15.

4 RodríGUEZ R, LibARDO. Derecho Administrativo. General y colombiano. Séptima Edición Ed. Temis. Santa Fe de Bogotá. 1994. p. 30.

5 Entendiendo por aquellos, todos los actos de las demás autoridades administrativas como son los dictados por los ministros, directores de departamentos administrativos, superin- 
Es por esto, por lo que las otras fuentes no pueden ir en contraposición de la Ley, ya sea porque no están cumpliendo con los procedimientos especiales de validez y eficacia y que fueron descritos con anterioridad, bien porque no representan la materialización del querer del pueblo sino simplemente la visión de unos órganos, ora porque la Constitución Nacional prescribe en todo momento al subordinación de aquellas fuentes a la Constitución y la Ley, de manera jerárquica y respectiva ${ }^{6}$.

\section{Respecto a la Ley de Prelación de Créditos}

Partiendo que la Ley es la expresión de la voluntad del pueblo, es prudente observar cómo se encuentra posicionado aquel asunto dentro el orden jerárquico piramidal de la prelación de créditos.

De antaño, el Derecho ha protegido al acreedor que deposita su confianza en un deudor, el cual ha entregado su palabra como garantía para cumplir lo debido y por ende se ha obligado; sobre aquel asunto jurídico-económico, cabe distinguir las primeras acciones creadas por el pretor y que se destinaban a la protección de los contratantes (acreedores) con las empresas (empresa -negotiatio- establecimiento -taberna instructa-) y que fueron conocidas como las acciones adyecticias -adiecticiae qualitatis- ${ }^{7}$, en particular las acciones que protegieron el sector de la administración de inmuebles urbanos, entre otras ${ }^{8}$.

Aquella protección es conocida como a favor del crédito -favor creditoris-, período de tiempo de las obligaciones que son a favor del acreedor, en la medida que se está proporcionando las herramientas necearías para lograr satisfacer las deudas a través de figuras como las hipotecas, prendas e incluso con el llamamiento de terceros que actúen como garantes.

En este sentido, muchas son las maneras de proteger las deudas y de la misma forma, diversas las condiciones de catalogar a los propios acreedores ${ }^{9}$;

tendencias, juntas directivas y directores, gerentes o presidentes de los establecimientos públicos, asambleas departamentales, gobernadores, concejos municipales, alcaldes y demás autoridades con capacidad decisoria. Ídem. p. 31

6 Respeto de la Constitución como fuente suprema ver UMBERTO BRECCIA, LiNA BIGLIAZZA Geri, Ugo Natoli, Franceso D. Busnelli. Derecho Civil. Normas, Sujetos y Relación Jurídica. Trad. FernANDo Hinestrosa. Tomo I. Vol. I. 1. a ed. Ed. Universidad Externado de Colombia. Bogotá. 1992. pp. 37 y ss.

$7 \mathrm{Al}$ respecto Cfr., PetruCCI, Aldo. Protección de quienes contratan con empresas comerciales en la experiencia jurídica romana. Aplicación de la acción institoria. Revista de Derecho Privado; n. ${ }^{\circ}$ 12-13., Bogotá. Universidad Externado de Colombia. 2007. pp. 179 y ss.

8 Ídem. p. 183.

9 Sobre el particular Cfr., en el Código Civil (C.C.) colombiano el Título XL artículos 2488 a 2511 en lo relativo al tema de la clasificación de los acreedores o la prelación de los créditos. 
lo relevante resulta ser que es la Ley, la que determina en qué orden se debe cancelar las acreencias ${ }^{10}$.

En síntesis, el Ordenamiento Jurídico colombiano relacionó a aquellos sujetos intervinientes en el mercado según el crédito existente, es decir que se hallan los créditos catalogados como de primera clase ${ }^{11}$, entendidos como las obligaciones que inicialmente se deben cancelar por la importancia y naturaleza propia de la concepción de los alimentos, las obligaciones laborales, costas judiciales y pagos al fisco. De igual forma, existen créditos de segunda clase $^{12}$ o compuestos por los acreedores prendarios, así como de tercera clase $e^{13}$ o acreencias hipotecarias; es de aclarar que sobre estas dos clases (segunda y tercera) mal puede declararse que se trata de prelación en la medida que son afectaciones ligadas o limitadas a objetos especiales ${ }^{14}$.

Finalmente se encuentran los créditos de cuarta clase ${ }^{15}$ así como los de quinta

10 Hinestrosa, Fernando. Tratado de las Obligaciones I. Concepto, Estructura, Vicisitudes. Tercera Edición. Ed. Universidad Externado de Colombia. Bogotá. 2007. pp. 693 y ss.

11 Créditos de Primera Clase. Art. 2495. C.C colombiano -

"(...) La primera clase de créditos comprende los que nacen de las causas que en seguida se enumeran: 1. Las costas judiciales que se causen en el interés general de los acreedores. 2. Las expensas funerales necesarias del deudor difunto. 3. Los gastos de la enfermedad de que haya fallecido el deudor. (...) 4. Subrogado. L. 165/41, art. $1^{\circ}$, L. 50/90, art. 36. Los salarios, sueldos y todas las prestaciones provenientes de contrato de trabajo. 5. Los artículos necesarios de subsistencia, suministrados al deudor y a su familia durante los últimos tres meses. (...) 6. Los créditos del fisco y los de las municipalidades por impuestos fiscales o municipales devengados. (...)". Subrayado en cursiva por fuera de texto.

12 Créditos de Segunda Clase. Art. 2497. C.C colombiano -

"(...) A la segunda clase de créditos pertenecen los de las personas que en seguida se enumeran: 1. El posadero sobre los efectos del deudor, (...) 2. El acarreador o empresario de transportes sobre los efectos acarreados que tenga en su poder o en el de sus agentes o dependientes, (...) 3. El acreedor prendario sobre la prenda. (...)". Subrayado en cursiva por fuera de texto.

13 Créditos de Tercera Clase. Art. 2499. C.C colombiano -

"(...) La tercera clase de créditos comprende los bipotecarios. (...)". Subrayado en cursiva por fuera de texto.

$14 \mathrm{Al}$ respecto ver la Sentencia de la Sala de Negocios Generales (SGN) de la Corte Suprema de Justicia (CSJ) de 22 de abril de 1941, LI, 897. Citado por Hinestrosa, Fernando. Ob. cit. p. 695 .

15 Créditos de Cuarta Clase. Art. 2502. C.C colombiano "(...) La cuarta clase de créditos comprende: 1. Los del fisco contra los recaudadores, administradores y rematadores de rentas y bienes fiscales. 2. Los de los establecimientos de caridad o de educación, costeados con fondos públicos, y los del común de los corregimientos contra los recaudadores, administradores y rematadores de sus bienes y rentas. 3. Derogado. D. 2820/74, art. 70. 4. Los de los bijos de familia por los bienes de su propiedad que administra el padre sobre los bienes de éste. 5 . Los de las personas que están bajo tutela y curaduría, contra sus respectivos tutores o curadores. 6. Derogado. D. 2820/74, art. 70. 7. Adicionado. L. 1116/2006, art. 124. Los de los proveedores de materias primas o insumos necesarios para la producción o transformación de bienes o para la prestación de servicios". ( ... "). Subrayado en cursiva por fuera de texto. 
clase $^{16}$, que hacen referencia a los acreedores quirografarios (Del griego kbéir -mano- y graphein - escritura- documento sin autorización de notario o ente oficial) o "a los bienes que no gozan de preferencia"17.

En el instante en que se distribuyen los activos del deudor, existe una preferencia en saldar los créditos a los acreedores; sin embargo y a pesar de no ser un tema que se tratará en este escrito dejando para otra oportunidad los comentarios sobre el particular, es prudente por lo menos advertir algunas consideraciones acerca de la figura de los acreedores privilegiados con garantía mobiliaria.

En virtud de la Ley 1676 de 2013 que cumple una función económica, las garantías mobiliarias hacen referencia a todas las operaciones que tengan como efecto avalar obligaciones ${ }^{18}$ de toda naturaleza con bienes muebles o mercantiles, considerados a favor de los acreedores garantizado ${ }^{19}{ }_{i}$ entendiendo por estos tanto a las personas naturales, jurídicas, entes gubernamentales, y hasta en mi consideración, con reserva, los patrimonios autónomos ${ }^{20}$.

16 Créditos de Quinta Clase. Art. 2509. C.C colombiano -

"(...) La quinta y última clase comprende los bienes que no gozan de preferencia. Los créditos de la quinta clase se cubrirán a prorrata sobre el sobrante de la masa concursada, sin consideración a su fecha. (...)". Subrayado en cursiva por fuera de texto.

17 Hinestrosa, Fernando. Ob. cit. p. 694.

18 En donde el crédito no resulta ser más que una herramienta del régimen de garantías.

19 Concepto de Garantía Mobiliaria y Ámbito de Aplicación. Art. 3. Ley 1676 de 2013.

"(...) Las garantías mobiliarias a que se refiere esta ley se constituirán a través de contratos que tienen el carácter de principales o por disposición de la ley sobre uno o varios bienes en garantía específicos, sobre activos circulantes, o sobre la totalidad de los bienes en garantía del garante, ya sean estos presentes o futuros, corporales o incorporales, o sobre los bienes derivados o atribuibles de los bienes en garantía susceptibles de valoración pecuniaria al momento de la constitución o posteriormente, con el fin de garantizar una o varias obligaciones propias o ajenas, sean de dar, hacer o no hacer, presentes o futuras sin importar la forma de la operación o quien sea el titular de los bienes en garantía. // (...), el concepto de garantía mobiliaria se refiere a toda operación que tenga como efecto garantizar una obligación con los bienes muebles del garante e incluye, entre otros, aquellos contratos, pactos o cláusulas utilizados para garantizar obligaciones respecto de bienes muebles, entre otros la venta con reserva de dominio, la prenda de establecimiento de comercio, las garantías y transferencias sobre cuentas por cobrar, incluyendo compras, cesiones en garantía, la consignación con fines de garantía y cualquier otra forma contemplada en la legislación con anterioridad a la presente ley.// Cuando en otras disposiciones legales se baga referencia a las normas sobre prenda, prenda civil o comercial, con tenencia o sin tenencia, prenda de establecimiento de comercio, prenda de acciones, anticresis, bonos de prenda, prenda agraria, prenda minera, prenda del derecho a explorar y explotar, volumen aprovechable o vuelo forestal, prenda de un crédito, prenda de marcas, patentes u otros derechos de análoga naturaleza, derecho de retención, y a otras similares, dichas figuras se considerarán garantías mobiliarias y se aplicará lo previsto por la presente ley. (...)" Subrayado en cursiva por fuera de texto.

20 Definiciones. Art. 8. Ley 1676 de 2013.-

"(...) Para efectos de la presente ley se entiende por: (...) Acreedor garantizado: La persona natural, jurídica, patrimonio autónomo, o entidad gubernamental en cuyo favor se constituye una garantía mobiliaria, con o sin tenencia. (...)" Subrayado en cursiva por fuera de texto. 
En aquel mismo sentido crítico, este acreedor privilegiado está posicionado de manera paralela a la pirámide de créditos ya comentada, poseyendo un derecho superior que obliga al deudor a satisfacer en primer lugar su compromiso garante antes de cumplir con los demás débitos a los que se ha obligado, suscitando una modificación mas no una derogatoria del régimen civil y comercial de la prelación de créditos, por el hecho de haber creado un nuevo tipo de acreedor privilegiado.

\section{Resolución}

En el mismo orden explicativo expuesto, el orden piramidal de las fuentes jurídicas seguirá marcando el entorno del tema del consumidor; inclusive, los actos administrativos emanados de los sujetos con funciones públicas deben ceñirse a las disposiciones legales o, en otros términos, los actos administrativos deben sujetarse a la misma Ley.

Las Resoluciones, que pertenecen a la categoría de actos administrativos y que son la expresión de la voluntad de un órgano encaminado a ejercer una función administrativa, logran tener la capacidad de generar efectos jurídicos en un caso en concreto. Es posible asumir que aquel acto administrativo está subordinado a la Ley y como consecuencia, solo puede regular y modificar situaciones hasta donde ésta se lo permita, sin ejecutarlo de forma diferente a lo ordenado por aquella, ni mucho menos, contrariando o interpretando sus instrucciones en forma indebida.

No obstante lo anterior, existen situaciones en las cuales una Resolución, entendida como acto administrativo, determina preceptos contrarios a la Ley, modificando casos en concreto que pueden servir como referencia para las demás situaciones particulares y beneficiándose de actos que contrarían las disposiciones legales; éstas actuaciones administrativas que pueden pasar desapercibidas dentro de nuestro Ordenamiento Jurídico, logran configurar una figura catalogada como de elusión constitucional.

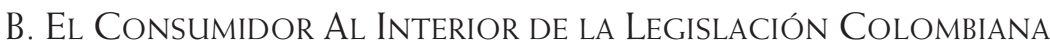

\section{Concepto y Evolución Normativa}

En aras de simplificar la noción del Consumidor, traeré a colación el significado descrito en la Ley 1480 de 2011 y en el que se estableció (Artículo 5) que por aquel debía pensarse en "(...) Toda persona natural o jurídica que, como destinatario final, adquiera, disfrute o utilice un determinado producto, cualquiera que sea su naturaleza para la satisfacción de una necesidad propia, privada, familiar o doméstica y empresarial cuando no esté ligada intrínsecamente a su actividad económica. Se entenderá incluido en el concepto de consumidor el de usuario. (...)". 
Asimismo, cabe recordar que son variadas las concepciones existentes de consumidor ${ }^{21}$, en la medida que el derecho del consumo se encuentra reglamentado de manera general en leyes y códigos, y de forma particular de acuerdo a los sectores de la economía ${ }^{22}$.

En igual medida, el Alto Tribunal de Justicia colombiano se ha pronunciado, incluso con anterioridad a la fecha de promulgación de la Ley sobre la concepción, estableciendo que no todo sujeto que interactúe en un mercado (tráfico de bienes y servicios), puede estar provisto de la calidad de consumidor.

Al respecto, pude acudirse a la Sentencia de la CSJ SC 072 del 3 de mayo de 2005 MP. Cesar Julio Valencia Copete, en la que de manera detalla describió que para acudir a tal concepción había de referenciarse desde el Artículo 78 la Constitución Nacional de $1991^{23}$ hasta en la misma exposición de motivos junto con las ponencias presentadas ante las cámaras, de la Ley 73 de 1981 que autorizó la expedición del Decreto 3466 de $1982^{24}$.

\section{El Consumidor Dentro del Sistema de Prelación de Créditos}

Una vez aclarado el asunto conceptual del consumidor, es hora de entrabarse en la discusión del escalamiento o la progresión en la percepción del acreedor, me explico; se ha tratado el tema del orden jerárquico piramidal de la prelación

21 Consumer Rights Act 2015, United Kingdom.

"(...) A 'consumer' under the CRA is an individual acting for purposes that are wholly or mainly outside that individual's trade, business, craft or profession. The inclusion of the wording "wholly or mainly" makes the definition of a consumer wider than current law so more people will be caught by this definition. (...)"

22 Hinestrosa, Fernando. Tratado de Obligaciones II. De las fuentes de las obligaciones: el negocio jurídico. Vol. II. Ed. Universidad Externado de Colombia. Bogotá. 2015. Pie de p. 4853 , p. 438.

"(...) Toda persona natural o jurídica que, como destinatario final, adquiera, disfrute o utilice un determinado producto, cualquiera que sea su naturaleza para la satisfacción de una necesidad propia, privada familiar o doméstica y empresarial cuando no esté ligada intrínsecamente a su actividad económica. Se entenderá incluido en el concepto de consumidor el de usuario $(\ldots)^{\prime \prime}$

Villalba Cuellar, Juan Carlos. Introducción al derecho del consumo. 1. ${ }^{a}$ ed. Ed. Universidad Militar Nueva Granada. 2012. pp. 93-96.

23 De los Derechos Colectivos y del Ambiente. Art. 78. Constitución Nacional-

"(...) La ley regulará el control de calidad de bienes y servicios ofrecidos y prestados a la comunidad, así como la información que debe suministrarse al público en su comercialización. // Serán responsables, de acuerdo con la ley, quienes en la producción y en la comercialización de bienes y servicios, atenten contra la salud, la seguridad y el adecuado aprovisionamiento a consumidores y usuarios. (...)" Subrayado en cursiva por fuera de texto.

24 Definiciones. Art. 1. Decreto 3466 de 1982-

"(...) Para los efectos del presente decreto, entiéndese (SIC) por: (...) c) Consumidor: Toda persona, natural o jurídica, que contrate la adquisición, utilización o disfrute de un bien o la prestación de un servicio determinado, para la satisfacción de una o más necesidades.

$(\ldots)^{\prime \prime}$ Subrayado en cursiva por fuera de texto. 
de créditos y dentro del mismo se establecía que aquella protección existente para el acreedor (favor creditoris) cobijaba el hecho de dotarlo de herramientas necesarias para satisfacer sus deudas -bipotecas, prendas, seguros-; no obstante, así como existían diversidad de formas de protección ${ }^{25}$, en la misma medida concurrían las condiciones para catalogar a los acreedores.

Tal y como se advirtió en otra oportunidad y sin el ánimo de ser repetitivo, de acuerdo al Ordenamiento Jurídico existen cinco órdenes de créditos que disponen de preferencia o prelación, con la aclaración de los créditos de segunda y tercera clase -Sent. SNG CSJ 22/04/41-26 ; dentro de aquella clasificación, resulta claro que en ningún orden aparecen la figura del consumidor como un acreedor privilegiado, más allá que dentro de los créditos que no llegan a gozar de preferencia, es decir al interior de los de quinta clase.

Es prudente determinar las razones existentes para clasificar la prelación de créditos, aparte de lo establecido sobre los acreedores privilegiados con garantía mobiliaria, es preciso esclarecer que cuando se está frente a créditos de primera clase, se halla ante algunos clasificados como de primera necesidad, así como los procedentes del propio proceso en interés de los acreedores (costas judiciales), y los originados de los gastos funerarios del deudor difunto o los de su última enfermedad.

En otro aspecto relacionado con esta clase, son los gastos generados por los salarios y prestaciones sociales, así como los artículos que requiera para subsistir el deudor y su familia durante los últimos tres meses junto con los créditos del fisco, sin desconocer las prendas agrarias y los alimentos judicialmente señalados.

En una segunda clase, se hallan los créditos pertenecientes a aquel posadero sobre los bienes del deudor y que aún permanecen en el mismo lugar, junto con los del transportador sobre los objetos acarreados, así como los originarios sobre la prenda frente al acreedor prendario ${ }^{27}{ }_{i}$ por otra parte y en este mismo orden, se encuentran los créditos hipotecarios, clasificados como de tercera clase.

La cuarta clase de créditos, ya relacionada en el acápite del Artículo 2502 del C.C. colombiano, comprende los egresos del fisco o los de los establecimientos de caridad, el de los hijos sobre los bienes que son administrados por sus padres, así como los gestionados por los tutores. Para finalmente hallar una quinta clase de créditos, que son aquellos que no logran gozar de ninguna

25 Sobre el factor garante del consumidor cabe recordar el elemento proteccionista que en todo momento involucra el sistema de tutela especial italiano. UMBERTO BRECCIA, LINA Bigliazza Geri, Ugo Natoli, Franceso D. Busnelli. Ob. cit. pp. 539 y ss. Idem.

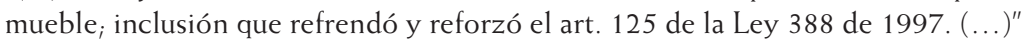


garantía o preferencia en un mercado y es precisamente este último punto el que se hace necesario aclarar.

Del Artículo 5 Ley 1480/11 se desprende que cualquier sujeto jurídicoeconómico que en general llega a adquirir, disfrutar o utilizar un producto y con el fin que a bien tenga exponer o el empresarial y sin que lo vincule a la actividad propia de la empresa, se encuentra dotado de la calidad de usuario o consumidor. En definitiva, un consumidor es el sujeto que "usa, desgasta, agota o extingue el producto, es decir, quien tiene una relación de consumo con el producto" ${ }^{\prime 28}$.

Por otra parte, si estamos frente a una situación económica, los sujetos que hacen parte de aquella deben, necesariamente, sujetar sus comportamientos a las reglas del mercado y es que la realidad económica determina los comportamientos de las partes. No obstante, la oscilación económica de los Mercados no puede ir en contra de las prescripciones legales establecidas, pese a la visión consecuencialista existente en la Economía.

Viene a mi memoria en este momento, un aparte de las tendencias económicas del consumidor ${ }^{29}$, en donde se catalogaba que si existía una escasez de productos, degeneraba con el tiempo en una mayor demanda y por tanto un aumento en el precio. De igual forma, cuando el consumidor adquiría un producto, debía asegurar que podía obtenerlo (quiere y puede); directamente vinculada con la anterior, una tercera variable económica que cabría traer a colación es la de considerar la capacidad adquisitiva, en la medida que si podía conseguir productos mayor sería su cantidad de consumo; para finalmente tratar una última variable como es la de la renta y su incidencia en el consumo ${ }^{30}$.

Aquellas variables económicas propias del consumidor, hacen que aquel sujeto enfrente el mercado con el suficiente deber de diligencia (duty of diligence) $\mathrm{y}$, en algunos casos, con la diligencia debida (due diligence) que amerita la volatilidad propia de estos escenarios económicos ${ }^{31}$.

Es decir, que si dentro de los deberes como consumidor se haya el de la información ${ }^{32}$, aquella obligación está orientada a los consumidores que en el

28 Velandia, Mauricio. Derecho de la Competencia y del Consumo. 2. ${ }^{a}$ ed. Ed. Universidad Externado de Colombia. Bogotá. 2011. p. 427.

29 Ídem. P. 425.

30 El consumo está directamente relacionado con el propio Ahorro, representando el $30 \%$ de los ingresos, mientras que el restante se ha de fragmentar en gastos de Transporte $20 \%$, Comida 30\%, Casa 18\%, Servicios Públicos 15\%, Medicinas 6\% y otros Gastos $11 \%$.

31 Cubillos Garzón, Camilo. Deberes en los Actos de Gestión al Interior de una Persona Jurídica.REVIST@E-Mercatoria, vol.7,n. ${ }^{\circ}$ 2. Bogotá: Universidad Externado de Colombia, 2008. Disponible en [http://www.emercatoria.edu.co/], consultada el 7 de junio de 2016.

32 Derechos y Deberes de los Consumidores y Usuarios. Art. 3. Numeral 2. Ley 1480 de 2011.-

"(...) Se tendrán como derechos y deberes generales de los consumidores y usuarios, sin perjuicio de los que les reconozcan leyes especiales, los siguientes: (...) //2. Deberes. //2.2. 
plano de acreedores diligentes, logran igualmente valorar el riesgo de la operación en la medida que el compromiso o la contingencia nunca se agotará con la simple garantía.

En aquel orden de ideas, valorar el riesgo de una operación implica en primer lugar calcular la probabilidad de la ocurrencia de los hechos; de la misma forma y en segundo término, apreciar el peligro significa la estimación del impacto que puede acarrear la verificación de aquellos hechos jurídicos; para finalmente comprender que calcular el peligro encarna la evaluación de la asignación o la tasación de quien asume el riesgo.

\section{RESPECTO A LA INTERPRETACION DISÍMIL DE UNA RESOLUCION}

\section{A. La Elusión como TéCniCa de Vulneración LeGislativa}

Antes de adentrarme en la interpretación normativa desigual, es prudente recordar que el Ordenamiento Jurídico de la libre competencia se encuentra cimentado en criterios generales que indican los deseos del legislador pero que se hallan controlados a través del propio mercado ${ }^{33}$.

Cuando se desconoce con en el transcurrir económico los parámetros jurídicos existentes, no existen razones de peso que desequilibren la balanza constitucional de la legalidad y la equidad ${ }^{34}$; aquellos movimientos análogos que tienden a prescindir de los controles constitucionales, sustraen de los textos normativos la razón de ser del mismo sin llegar a ejecutar la modificación propia de la Ley o su derogatoria ${ }^{35}$.

En general, las causas que llevan a prescindir de los pasos modificatorios constitucionales, se reducen a circunstancias sociales, económicas y me atrevería a decir, también políticas. No obstante lo anterior, múltiples pueden ser los fundamentos que motivan las diversas actuaciones, pero el desconocer los pasos

Informarse respecto de la calidad de los productos, así como de las instrucciones que suministre el productor o proveedor en relación con su adecuado uso o consumo, conservación e instalación. // 2.2. Obrar de buena fe frente a los productores y proveedores y frente a las autoridades públicas. // 2.3. Cumplir con las normas sobre reciclaje y disposición de desechos de bienes consumidos. (...)" Subrayado en cursiva por fuera de texto.

33 Uribe Piedrahita, Carlos Andrés. Reforma al régimen de Libre Competencia en Colombia. -Perspectivas y Retos-. Grupo Editorial Ibáñez. Bogotá. 2010. p. 79.

34 Quinche Ramirez, Manuel Fernando. La Elusión Constitucional: Una Política de Evasión del Control Constitucional en Colombia. Segunda Edición. Editorial Universidad del Rosario. Bogotá. 2009. p. 34.

35 CuBILLOS GARZÓN, CAMILO. La manipulación constitucional y los errores en la reglamentación de las normas mercantiles.REVIST@E-Mercatoria, vol. 11,n. ${ }^{\circ}$ 1. Bogotá: Universidad Externado de Colombia, 2012 Disponible en [http://www.emercatoria.edu.co/], consultada el 7 de junio de 2016. 
en la elaboración de las normas jurídicas significa, independientemente de la finalidad, que se está empleando actuaciones dolosos mas no altruistas, como bien podría pretender exponer al resguardarse en la figura de un consumidor ${ }^{36}$.

El excluir el trámite legislativo es procurar desprenderse de la histórica y evolutiva $^{37}$ garantía constitucional de la reserva de Ley ${ }_{i}$ es decir considerar aquella posibilidad mimética ${ }^{38}$, sería tanto como apartarse del principio de que solo a través de una Ley formal se puede regular o modificar una norma.

Ahora bien, el 30 de marzo de 2015 a través de la Resolución 13895 de la $\mathrm{SIC}$, en mi concepto, se trasgredieron los controles constitucionales existentes para reformar la Ley en la medida que se desconoció el Ordenamiento Civil colombiano cuando se excluyó el orden de prelación de los créditos, tratándose de los acreedores privilegiados.

Así mismo, bajo la misma linea argumentativa, en un caso paralelo a dicha investigacion, el Tribunal Superior del Circuito de Bogotá, mediante sentencia del 7 de septiembre de $2016^{39}$, resolvió el recurso de apelación contra la sentencia proferida por la SIC el 21 de enero de 2016. En el presente, el Tribunal ordenó que los valores reconocidos en el proceso debían incluirse por los liquidadores de las sociedades demandadas dentro del grupo de gastos de administración.

En términos generales, argumentó la SIC y el Tribunal que, en uso de las facultades legales conferidas, con el fin de proteger los derechos como consumidores o acreedores que adquirieron una vivienda, se ordenó como medida preventiva a empresas en reorganización y, algunos casos en liquidación judicial, pagar los auxilios de habitabilidad a los residentes evacuados de unas urbanizaciones o de unos conjuntos residenciales.

Situación aquella que en mi concepto, atenta contra la posición previamente establecida en el Ordenamiento civil de la existencia de una prelación de los créditos; cuando se dispuso en su Título XL que debían existir la preferencia y para ello se concibió que esta prioridad se presentaba bajo el entendido de

36 SAgÜES, NeSTOR. Reflexiones sobre la manipulación constitucional. En: "Perspectivas del Derecho Procesal Constitucional". Universidad del Rosario. Bogotá. 2007. p. 23. (Sic) Citado por Quinche RamireZ, Manuel Fernando. Ob. cit. p. 20.

37 Sierra Porto, Humberto. Concepto y Tipos de Ley en la Constitución Colombiana. Editorial Universidad Externado de Colombia. Bogotá. 1998.

38 QuinChe RAmiReZ, MANUel FERnANDO. Ob. cit. p. 32. Respecto a la elusión legislativa, aquella es definida como

"(...) una manipulación, maniobra o procedimiento, aparentemente válido en su forma, por medio del cual el Congreso evita el debate o votación de un tema específico o de una proposición aditiva, al amparo del trámite general de las iniciativas, de modo tal, que mediante la mimesis del trámite, se obtiene como resultado la aprobación del texto o del tema, evitándose así el control de la iniciativa, encarnado en el debate y en la votación congresional. (...)"

39 Sentencia del Tribunal Superior del Circuito de Bogotá del 7 de septiembre de 2016. 
valorar cada uno de las garantías, considerándolas en un orden de importancia por el significado económico y su relevancia social ${ }^{40}$.

Así entonces se comprendió, con la salvedad de los acreedores privilegiados con garantía mobiliaria, que en primer lugar (Art. 2495. C.C colombiano) debía cancelarse los créditos que tuvieran relevancia y fue así que se pensó en los generados por alimentos, costas judiciales, gastos funerarios, laborales y a Hacienda.

En la misma medida y como segunda clase (Art. 2497. C.C colombiano) se concibieron los egresos de los acreedores prendarios; en tercer grado de importancia (Art. 2499. C.C colombiano), se hallan los acreedores hipotecarios; en cuarto nivel (Art. 2502. C.C colombiano) se encuentran las expensas de los establecimientos de caridad, los bienes de los hijos de familia administrados por el padre o el de las personas bajo tutela o curaduría junto con los de los proveedores de materias primas.

Finalmente, se encuentran los relacionados en un quinto lugar (Art. 2509. C.C colombiano) y que hacen referencia a los créditos que no gozan de ninguna preferencia y en donde cabría catalogar a aquellos acreedores que, teniendo la oportunidad, voluntariamente eligieron no entrar a privilegiar sus créditos; me refiero precisamente a los consumidores o a los acreedores de las viviendas en el caso en comento.

No pretendo de esta forma desconocer el daño que se causa a los consumidores, no intento desestimar o ignorar la responsabilidad existente por pate de las empresas constructoras, simplemente pongo en conocimiento la perspectiva de no valerse de argumentos a favor del consumidor que resultan confusos por desconocer las garantías constitucionales propias de la Ley.

Así mismo, la Superintendencia de Sociedades, en pronunciamiento del 24 de febrero de $2017^{41}$, sostuvo que se iba a respetar la prelación de créditos, y que de esa forma, la liquidación de la empresa se iba a tramitar con las disposiciones legales prescritas en el Ordenamiento Civil.

El respeto o la aceptación de la prelación de créditos hacen que no se pueda desechar su aplicabilidad, por tanto, su desconocimiento significa no compartir lo que previamente se estableció en la Ley y optar por la posición de "economizar" todo un trámite constitucional para efectos de modificar o derogar aquella Ley e instaurar por los motivos que existan, la posición que se considere más oportuna.

40 En materia concursal, se ha considerado que determinar la masa pasiva significa distinguir también los créditos contra aquella masa, los créditos concursales y los créditos subordinados; de igual forma, se debe clasificar a los acreedores, entre privilegiados, ordinarios y subordinados. Sobre el particular Cfr VeIGA Copo, Abel B. Créditos e Insolvencia. 1. ${ }^{a}$ ed. Ed. Colección Textos de Jurisprudencia. Bogotá. 2009. pp. 496 y ss.

41 Audiencia CDO CALAMAR SAS Parte 1 del 24 de febrero de 2017 de la Superintendencia de Sociedades https://livestream.com/supersociedades/CDOCalamarSAS/videos/150339699. Última fecha de revisión: 17 de julio de 2017 


\section{B. RESPECTO DE OtRAS IRREGULARIDADES LEGALES DE LA ReSOluCiÓN 13895 DE 2015 DE LA SIC}

En este mismo orden anormal, es prudente observar que no simplemente se trata de haber eludido el trámite constitucional de modificar la Ley de la prelación de créditos, sino que del mismo modo se desconocieron otros parámetros que cabe a desarrollar.

Cuando la SIC en sus consideraciones reconoce que al no existir un "mecanismo diferente que de forma inmediata restablezca el goce efectivo de los inmuebles a las familias que han sido evacuadas" le corresponde a aquella entidad en un uso aparente, ejercer las facultades legales a fin de proteger los derechos fundamentales de los consumidores.

En este estado, cabe recordar la función tuitiva de la rama judicial y de cómo la acción de tutela consagrada en el Art. 86 de la C.N establece que toda persona tendrá acción de tutela para reclamar ANTE CUALQUIER JUEZ, la protección inmediata de sus derechos constitucionales fundamentales.

De igual forma, el Art. 59 de la Ley 1480 de 2011 determina que dentro de las actuaciones administrativas, se halla las de velar por la observancia de las disposiciones de esa ley y ordenar las medidas necesarias para evitar que se cause daño a los consumidores, así como el Art. 12 del Decreto 4886 de 2011 determina que como funciones de la entidad se halla la de decidir y tramitar las investigaciones administrativa sobre protección al consumidor e imponer las sanciones, medidas e inobservancia de las mismas órdenes de la SIC.

Estas normas que permiten aquellas facultades de la entidad, no dan pie para desconocer a través de interpretaciones erradas los otros campos jurídicos (constitucionales) existentes; las medidas de salvaguarda se pueden tomar, sin embargo, no pueden a través de ellas vulnerarse otros escenarios legales como resulta ser, para el caso en concreto, el de la prelación de los créditos.

Ya para finalizar y simplemente en orden aclaratorio, cuando la entidad resolvió ordenar a las entidades del Grupo Empresarial CDO el reconocimiento y pago de los créditos quirografarios representados en los auxilios de habitabilidad a los consumidores, no entró a aclarar si dicha responsabilidad era del orden solidario o subordinado, en la medida que simplemente estableció que las subordinadas de un grupo junto con la matriz de la misma, debían responder en conjunto (-Y-) o igualmente debían hacerlo por separado (-O- $)^{42}$.

42 En la parte resolutiva de la Resolución 13895 de 2015 de la SIC se estableció en el Artículo Segundo:

"(...) ORDENAR como medida preventiva a Alsacia Constructora de Obras S.A. -ALSACIA CDO S.A. EN REORGANIZACIÓN EMPRESARIAL (...) Y Y/O a la sociedad Calamar Constructora de Obras S.A.S. -CALAMAR CDO S.AS. EN REORGANIZACÓN EMPRESARIAL (...), en su condición de matriz de Grupo Empresarial CDO, el reconocimiento y pago de un auxilio 


\section{CONCLUSIONES}

1. La concepción del consumidor se ha forjado como consecuencia de las mismas fuentes jurídicas del Derecho (LEY), por tanto, el pretender modificar el contexto donde está circunscrito acarrea una variación a la misma Ley o lo que significaría que dicho cambio en su expedición, se sujetaría al máximo órgano democrático (CONGRESO).

2. Privar del trámite constitucional de modificación a través del Congreso, indicaría un actuar artificioso que se escuda en una figura altruista, como resultaría ser la de los derechos del consumidor.

3. Partiendo de la base que el consumidor es simplemente un sujeto jurídico que tiene una relación de consumo con los productos y si dentro de la Ley de prelación de créditos aquel sujeto se convierte en un acreedor y bajo el deber de diligencia no opta por salvaguardar, en mejor medida, su crédito, el mismo Ordenamiento civil lo cataloga como un tenedor de quinta clase o lo que es lo mismo, un acreedor quirografario.

4. El deber de diligencia existente en el consumidor, conlleva a que al interior de un mercado aquel sujeto deba necesariamente entrar a valorar el riego calculando bien sea la probabilidad de la ocurrencia de los hechos, la estimación del impacto y la evaluación de quien asume el riego o asignación del mismo.

5. Cuando un organismo de vigilancia, inspección y control ordena, bajo la figura de una "medida cautelar" cancelar unos créditos desconociendo la prelación existente en el propio Ordenamiento Jurídico, no solo es una conducta tachable sino que la misma se acentúa cuando además convierte sus decisiones en armas de doble filo al dejar en el aire un asunto como el de la responsabilidad solidaria y subordinada, así como el de la competencia constitucional al considerar que bajo facultades miméticas se halla simplemente protegiendo los derechos fundamentales.

\section{BIBLIOGRAFÍA}

Audiencia CDO Calamar SAS Parte 1 del 24 de febrero de 2017 de la Superintendencia de Sociedades https://livestream.com/supersociedades/CDOCalamarSAS/ videos/150339699. Última fecha de revisión: 17 de julio de 2017.

Consumer Rights Act 2015, United Kingdom.

Cubillos Garzón, CAMiLo. La manipulación constitucional y los errores en la reglamentación de las normas mercantiles.REVIST@E-Mercatoria, vol. 11,n.․․ 1. 
Bogotá: Universidad Externado de Colombia, 2012 Disponible en [http://www. emercatoria.edu.co/], consultada el 7 de junio de 2016.

Cubillos Garzón, Camilo. Deberes en los Actos de Gestión al Interior de una Persona Jurídica.REVIST@E-Mercatoria,vol.7,n. ${ }^{\circ}$ 2. Bogotá: Universidad Externado de Colombia, 2008. Disponible en [http://www.emercatoria.edu.co/], consultada el 7 de junio de 2016.

Hinestrosa, Fernando. Tratado de las Obligaciones I. Concepto, Estructura, Vicisitudes. 3. ${ }^{a}$ ed. Ed. Universidad Externado de Colombia. Bogotá. 2007.

Hinestrosa, Fernando. Tratado de Obligaciones II. De las fuentes de las obligaciones: el negocio jurídico. Vol. II. Ed. Universidad Externado de Colombia. Bogotá. 2015.

Ordenamiento Jurídico Colombiano:

- Código Civil

- Constitución Nacional

- Decreto 3466 de 1982

- Ley 73 de 1981

- Ley 1480 de 2011

- Ley 1676 de 2013

Petrucci, Aldo. Protección de quienes contratan con empresas comerciales en la experiencia jurídica romana. Aplicación de la acción institoria. Revista de Derecho Privado; $^{\circ}{ }^{\circ}$ 12-13., Bogotá. Universidad Externado de Colombia. 2007. pp. 179 y ss.

Quinche Ramirez, Manuel Fernando. La Elusión Constitucional: Una Política de Evasión del Control Constitucional en Colombia. 2. ${ }^{a}$ ed. Editorial Universidad del Rosario. Bogotá. 2009. p. 34.

Resolución 13895 de 2015 de la SIC.

RodríGUEz R., Libardo. Derecho Administrativo. General y colombiano. 7. ed. Ed. Temis. Bogotá. 1994. p. 30.

Sentencia de la Corte Suprema de Justicia 072 del 3 de mayo de 2005, MP. Cesar Julio Valencia Copete.

Sentencia del Tribunal Superior del Circuito de Bogotá del 7 de septiembre de 2016. 
Sierra Porto, Humberto. Concepto y Tipos de Ley en la Constitución Colombiana. Universidad Externado de Colombia. Bogotá. 1998.

Umberto Breccia, Lina Bigliazza Geri, Ugo Natoli, Franceso D. Busnelli. Derecho Civil. Normas, Sujetos y Relación Jurídica. Trad. Fernando Hinestrosa. Tomo I. Vol. I. 1. a ed. Universidad Externado de Colombia. Bogotá. 1992. pp. 37 y ss.

Uribe Piedrahita, Carlos Andrés. Reforma al régimen de Libre Competencia en Colombia. -Perspectivas y Retos-. Grupo Editorial Ibáñez. Bogotá. 2010. p. 79.

Veiga Copo, Abel B. Créditos e Insolvencia. Colección Textos de Jurisprudencia. Bogotá. 2009. pp. 496 y ss.

Velandia, Mauricio. Derecho de la Competencia y del Consumo. 2. ${ }^{a}$ ed. Universidad Externado de Colombia. Bogotá. 2011. p. 427.

Vidal Perdomo, Jaime. Derecho Administrativo. 9. ${ }^{a}$ ed. Edit. Temis. Bogotá. 1987. p. 15 .

Villalba CuellaR, Juan Carlos. Introducción al derecho del consumo. Universidad Militar Nueva Granada. 2012. 